\section{BMJ Paediatrics Open}

\title{
Survey of young people in one region of the UK on accessing COVID-19 information (SOCIAL)
}

Oliver G P Lawton, ${ }^{1}$ Sarah A Lawton (D , ${ }^{2}$ Lisa Dikomitis, ${ }^{3}$ Joanne Protheroe, ${ }^{3}$ Joanne Smith, ${ }^{2}$ Christian D Mallen ${ }^{3}$

To cite: Lawton OGP, Lawton SA, Dikomitis L, et al. Survey of young people in one region of the UK on accessing COVID-19 information (SOCIAL). BMJ Paediatrics Open 2021;5:e000942. doi:10.1136/ bmjpo-2020-000942

Received 10 November 2020 Accepted 4 January 2021
Check for updates

(C) Author(s) (or their employer(s)) 2021. Re-use permitted under CC BY-NC. No commercial re-use. See rights and permissions. Published by BMJ.

${ }^{1}$ St Joseph's Catholic College, Stoke on Trent, UK ${ }^{2}$ Keele CTU, Faculty of Medicine and Health Sciences, Keele University, Keele, UK

${ }^{3}$ Faculty of Medicine and Health Sciences, Keele University, Keele, UK

Correspondence to Sarah A Lawton; s.a.lawton@ keele.ac.uk

\section{ABSTRACT}

COVID-19 has significantly impacted young people's lives yet little is known about the COVID-19 related sources of information they access. We performed a cross-sectional survey of pupils (11-16 years) in North Staffordshire, UK. 408 (23\%) pupils responded to an online survey emailed to them by their school. Descriptive statistics were used to summarise the data. Social media, accessed by $68 \%$, played a significant role in the provision of information, despite it not being considered trustworthy. $89 \%$ felt that COVID-19 had negatively affected their education. Gaps in the provision of information on COVID-19 have been identified.

\section{BACKGROUND}

The Coronavirus disease (COVID-19) was characterised as pandemic in March 2020 by WHO. There is limited information available, on the impact COVID-19 is having on young people. Buzzi et $a l^{1}$ report that almost $40 \%$ of adolescents felt there would be 'a lot' of consequences to their education. Data on COVID-19 information sources accessed by young people is currently lacking.

The aim of the Study Of Covid-19 Information AccessibiLity for young people in North Staffordshire was to investigate whether young people aged 11-16 years had access to reliable information on COVID19 , how they accessed this information and the perception of COVID-19 impact on their education.

\section{METHOD}

A cross-sectional survey was administered to secondary school pupils (11-16 years) via email. Seven secondary schools in North Staffordshire (UK) were approached to participate, with two agreeing to. Schools sent pupils an email (Keele University Ethics: MH-200137) providing an introduction to the study and an online anonymous questionnaire link. The survey was hosted on an open access online platform, with Data Protection Act 2018 compliance.

Research questions were generated by the lead author based on personal experience. The survey was piloted on five young people and feedback incorporated. The survey included questions on: frequency with which pupils update themselves on COVID-19 information and sources they access; source trustworthiness and understanding; effect of COVID-19 on education; and information pupils want from schools on COVID-19. Descriptive analyses were used to summarise results.

\section{RESULTS}

A total of $408(23 \%)$ responses were obtained. The proportion of females participating increased incrementally with age (56\% aged 11 , to $74 \%$ aged 16 ). The mean age of respondents was 13.9 years and $88 \%$ identified their ethnicity as either White or Asian.

A total of $92 \%$ of participants have daily access to the internet on a personal device. When asked how often they updated themselves on COVID-19 at the start of the pandemic, $46 \%$ responded on a 'daily' basis. When asked the same question at the point of survey completion (July 2020), 'daily' updates were only reported by $10 \%$ of pupils (table 1 ). Older respondents updated more frequently $(66 \%$ of 16-year-olds updating 'daily', compared with $22 \%$ of 11-year-olds). Responders accessed multiple information sources (table 2). 'Television news' (72\%) was the most trusted source $(60 \%)$, although only 'best understood' by $26 \%$. Social media was an information source accessed by $68 \%$ of pupils, although this was not considered as trustworthy. 
Table 1 Frequency of accessing COVID-19 developments

\begin{tabular}{lccrr}
\hline & \multicolumn{3}{l}{ Frequency of update } \\
\cline { 2 - 5 } & When schools closed (March 2020) $\mathbf{n}$ (\%) & July 2020 $\mathbf{n ~ ( \% ) ~}$ \\
\hline Hourly & 13 & 3.2 & 1 & 0.2 \\
Daily & 187 & 45.9 & 41 & 10.1 \\
2-3 times a week & 103 & 25.2 & 119 & 29.3 \\
Once a week & 67 & 16.4 & 117 & 28.9 \\
Less than once a week & 27 & 6.6 & 104 & 25.6 \\
Never & 11 & 2.7 & 24 & 5.9 \\
\hline Total & $\mathbf{4 0 8}$ & $\mathbf{1 0 0}$ & $\mathbf{4 0 6}$ & $\mathbf{1 0 0}$ \\
\hline
\end{tabular}

*In two cases there were missing data.

Eighty-nine per cent of pupils felt that 'to some degree' COVID-19 had negatively affected their education. Respondents felt that schools should be providing more information, including information on: COVID-19 rules, government regulations and how best to keep safe (30\%); the wider impact of COVID-19 and global news (25\%); and plans to return to the classroom $(21 \%)$.

\section{CONCLUSIONS}

Pupils were concerned about the impact of COVID-19 on their education; findings which have also been reported in published studies elsewhere. ${ }^{1}$ A variety of information sources were accessed, often on a frequent basis, despite acknowledgement that the information may not have been accurate.

This research is limited by including a single geographical region and by recruiting at the end of the academic year, when pupils may not have been accessing their school email accounts. Teacher facilitated questionnaire completion may have increased response rates. ${ }^{2}$ Email invitations were administered by teachers rather than recognised national bodies that may have encouraged participation.

Findings demonstrate gaps in the provision of information on COVID-19 for young people, who would like schools to take a more prominent role in

Table 2 Sources of COVID-19 development updates participants accessed with sources trusted most and least, and understood best

\begin{tabular}{|c|c|c|c|c|c|c|c|c|}
\hline & Acce & & Trus & & Trust & & Unde & \\
\hline & $\mathbf{n}$ & $\%$ & $\mathbf{n}$ & $\%$ & $\mathbf{n}$ & $\%$ & $\mathbf{n}$ & $\%$ \\
\hline Television news & 292 & 71.6 & 244 & 59.8 & 13 & 3.2 & 105 & 25.9 \\
\hline Discussion with parents & 283 & 69.4 & 44 & 10.8 & 3 & 0.7 & 103 & 25.4 \\
\hline Internet news & 262 & 64.2 & 45 & 11.0 & 35 & 8.6 & 46 & 11.4 \\
\hline Discussion with friends & 177 & 43.4 & 2 & 0.5 & 32 & 7.9 & 8 & 2.0 \\
\hline Instagram & 168 & 41.2 & 2 & 0.5 & 57 & 14.1 & 19 & 4.7 \\
\hline TikTok & 149 & 36.5 & 6 & 1.5 & 146 & 36.0 & 52 & 12.8 \\
\hline YouTube & 130 & 31.9 & 12 & 2.9 & 11 & 2.7 & 21 & 5.2 \\
\hline Radio & 124 & 30.4 & 15 & 3.7 & 1 & 0.2 & 6 & 1.5 \\
\hline Snapchat & 107 & 26.2 & 2 & 0.5 & 42 & 10.4 & 10 & 2.5 \\
\hline Twitter & 46 & 11.3 & 8 & 2.0 & 14 & 3.5 & 16 & 4.0 \\
\hline Newspapers/Magazines & 41 & 10.0 & 4 & 1.0 & 17 & 4.2 & 6 & 1.5 \\
\hline Facebook & 37 & 9.1 & 2 & 0.5 & 29 & 7.2 & 2 & 0.5 \\
\hline Discussion with teachers & 26 & 6.4 & - & - & 1 & 0.2 & 1 & 0.2 \\
\hline Discussion with HCPs & 16 & 3.9 & 21 & 5.1 & - & - & 9 & 2.2 \\
\hline Other & - & - & 1 & 0.2 & 1 & 1.0 & 1 & 0.2 \\
\hline Total & & & 408 & 100 & $405^{\star}$ & 100 & $405^{\star}$ & 100 \\
\hline
\end{tabular}

${ }^{*}$ In three cases there were missing data. 
the provision of information. With internet use widespread, it is important that young people have clear, accurate information available to them, to increase understanding. ${ }^{3}$

Acknowledgements St Joseph's Catholic College, London Road, Trent Vale, Stoke-on-Trent, Staffordshire, ST4 5NT, UK; St John Fisher Catholic College, Ashfields New Road, Newcastle Under Lyme, Staffordshire, ST5 2SJ, UK.

Contributors This study was a collaboration between all authors. OGPL and SAL had full access to the data and take responsibility for data integrity and accuracy of data analysis. CDM was the chief investigator. OGPL produced the first draft of the manuscript. JS and SAL led the administrative, technical and material support. All authors contributed to the drafting and approval of the final manuscript.

Funding CDM is funded by the National Institute for Health Research (NIHR) Applied Research Collaboration West Midlands, the National Institute for Health Research (NIHR) School for Primary Care Research and a National Institute for Health Research (NIHR) Research Professorship in General Practice (NIHR-RP2014-04-026) for this research project. All authors had full access to the full data in the study and accept responsibility to submit for publication.

Disclaimer The views expressed are those of the author(s) and not necessarily those of the NIHR or the Department of Health and Social Care.

Patient and public involvement Patients and/or the public were involved in the design and conduct of this research. Refer to the Methods section for further details.
Patient consent for publication Not required.

Ethics approval Ethical approval was obtained by Keele University Faculty of Medicine and Health Sciences Research Ethics Committee on 13 July 2020, ref MH-200137.

Provenance and peer review Not commissioned; externally peer reviewed.

Open access This is an open access article distributed in accordance with the Creative Commons Attribution Non Commercial (CC BY-NC 4.0) license, which permits others to distribute, remix, adapt, build upon this work non-commercially, and license their derivative works on different terms, provided the original work is properly cited, appropriate credit is given, any changes made indicated, and the use is non-commercial. See: http://creativecommons.org/licenses/by-nc/4.0/.

ORCID iD

Sarah A Lawton http://orcid.org/0000-0002-8909-2057

\section{REFERENCES}

1 Buzzi C, Tucci M, Ciprandi R, et al. The psycho-social effects of COVID-19 on Italian adolescents' attitudes and behaviors. Ital J Pediatr 2020;46:1-7.

2 Gobina I, Villberg J, Välimaa R, et al. Prevalence of self-reported chronic pain among adolescents: evidence from 42 countries and regions. Eur J Pain 2019;23:316-26.

3 Nutbeam D. Health literacy as a public health goal: a challenge for contemporary health education and communication strategies into the 21st century. Health Promot Int 2000;15:259-67. 